\title{
Comparison of Local Anesthetic Efficacy of Lidocaine Gel and Lidocaine Gel-Intramuscular Diclofenac Combination in Patients Undergoing Flexible Cystoscopy
}

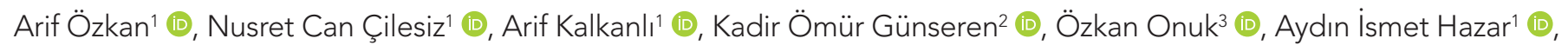 \\ Mustafa Bahadır Can Balcı' (1)
}

1Department of Urology, University of Health Sciences Gaziosmanpaşa Taksim Training and Research Hospital, İstanbul, Turkey ${ }^{2}$ Department of Urology, Uludağ University School of Medicine, Bursa, Turkey

32Department of Urology, Yeni Yüzyıl University School of Medicine, İstanbul, Turkey

Cite this article as: Özkan A, Çilesiz NC, Kalkanlı A, Günseren KÖ, Onuk Ö, Hazar Ai, et al. Comparison of Local Anesthetic Efficacy of Lidocaine Gel and Lidocaine Gel-Intramuscular Diclofenac Combination in Patients Undergoing Flexible Cystoscopy. JAREM 2018; 8(3): 157-60.

\begin{abstract}
Objective: In this study, we aimed to investigate the effects of $2 \%$ lidocaine gel only and $2 \%$ lidocaine gel-diclofenac combination on pain in male patients undergoing flexible cystoscopy.

Methods: The records of male patients who underwent flexible cystoscopy for lower urinary system symptoms and bladder tumor contol cystoscopy between April 2016, and April 2017, were reviewed. Patients with active urinary infection, urethral stricture, additional procedures during cystoscopy like biopsy, catheter withdrawal, or insertion, and sensory neurological defects were excluded from the study. Patients were divided into two groups according to the analgesic used. Overall, 116 patients in Group I were treated with 2\% lidocaine gel, and patients in Group II were treated with 2\% lidocaine gel and intramuscular diclofenac. In the gel group, $10 \mathrm{cc}$ of $2 \%$ lidocaine gel was instilled into the urethra 15 min before the procedure and immediately before the procedure. In the other group, $75 \mathrm{mg}$ diclofenac was intramuscularly administered 30 min before the $2 \%$ lidocaine gel instillation. All operations were performed by the same urologist. VAS scores were filled after the procedure, and the groups were compared.

Results: The mean age of the patients was $61 \pm 13.1$ years in Group I and $59 \pm 13.2$ years in Group II $(p=0.060)$. The mean duration of the procedure was $341 \pm 427$ in Group I and $342 \pm 51.1$ in Group II ( $p=0.586)$. There was a statistically significant difference between the groups in pain scores (group I: $6.1 \pm 2.5$; group II: $4.3 \pm 1.7 ; p<0.001$ ).

Conclusion: Intravenous administration of diclofenac, which was performed 30 min before the use of $2 \%$ lidocaine gel in males undergoing flexible cystoscopy, provides more effective analgesia than urethral gel alone.

Keywords: Flexible cystoscopy, analgesia, lidocaine gel, diclofenac
\end{abstract}

ORCID IDs of the authors: A.Ö. 0000-0001-6534-5403; N.C.Ç. 0000-0003-2115-698; A.K. 0000-0001-6509-4720; K.Ö.G. 0000-0001-8673-3093; Ö.0. 00000001-6497-0418; A.I.H. 0000-0001-5193-2340; M.B.C.B. 0000-0003-0395-1154.

\section{INTRODUCTION}

In daily urology practice, cystoscopy has been performed as an easy, reliable, and effective method, both in diagnosing the lower urinary tract symptoms and diagnosing and follow-up of bladder tumors as a day-case procedure for many years (1). While generally rigid tools had been used until the mid-1990s, today, flexible tools are used in office conditions (2). The procedure is painful and uncomfortable for the patient. The pain is reduced by using flexible instruments. However, anesthesia and analgesia management are very important since cystoscopy is usually an intervention in the office environment or outpatient clinic conditions. Cystoscopy procedure is probably more comfortable and painless in women than in men due to the short urethral pathway
(3). Starting with the first cystoscopy performed with cocaine anesthesia in 1884, the most appropriate analgesia and anesthesia methods have been investigated. However, there is no clear consensus on the amount, type, and duration of anesthesia used prior to cystoscopy. Today, a topical lidocaine gel is the most commonly used agent in cystoscopy because of its lubricant and local anesthetic effects (4). However, there are not many data available on the use of intramuscular non-steroidal anti-inflammatory drugs (NSAID).

The aim of this study was to determine whether the use of intramuscular diclofenac in addition to intraurethral local anesthetic gel predominate in the control of pain felt by the male patients during flexible cystoscopy. 


\section{METHODS}

A total of 209 male patients who underwent flexible cystoscopy either for diagnosis of lower urinary tract symptoms or for the follow-up of bladder tumors were included in the study between April 2016 and April 2017. The study was conducted in accordance with the Declaration of Helsinki. Patients with an active urinary tract infection, urethral stricture, those who had additional procedures such as biopsy or catheter pulling or insertion during cystoscopy, and who had sensory neurological deficits were excluded from the study.

Patients were divided into two groups with demographically similar properties according to the type of analgesia used. After briefing and written informed consent were obtained, the bladders of the patients were emptied before the procedure. In the first group (Group I), 116 patients received 2\% lidocaine gel, and in the second group (Group II), 93 patients received intramuscular $75 \mathrm{mg}$ diclofenac in addition to the gel. In Group I, 15 minutes before and immediately before the procedure, $10 \mathrm{cc} 2 \%$ lidocaine gel was instilled into the urethra; to prevent urethral escape, compression was applied to the glans penis using sterile gauze. Group II received intramuscular 75 mg diclofenac 30

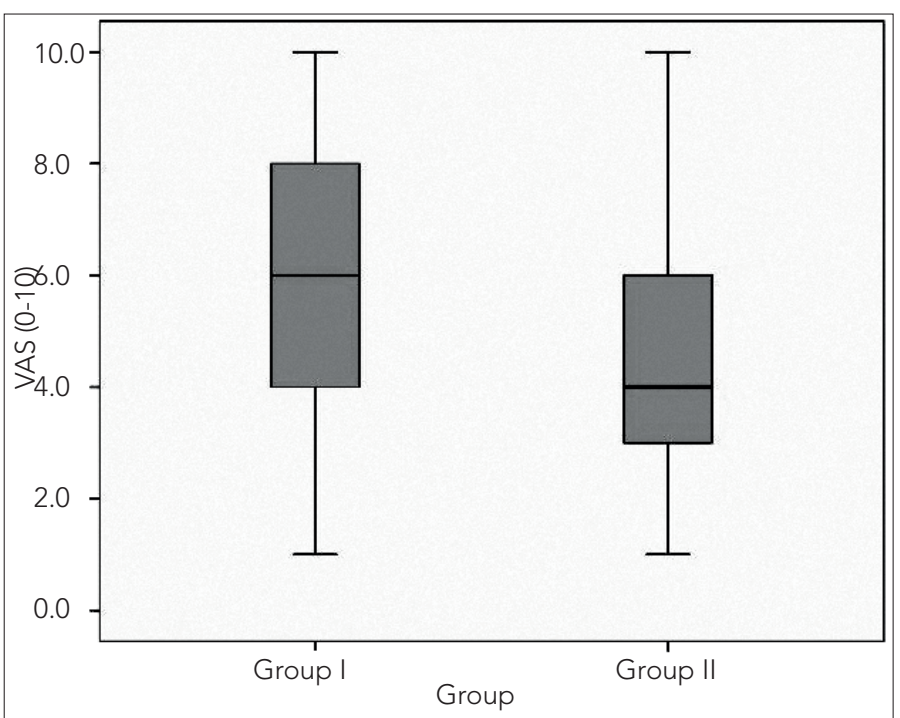

Figure 1. VAS distributions of group I and group I|

Table 1. Demographic and clinical data of the study groups

\begin{tabular}{|c|c|c|c|c|c|}
\hline & \multicolumn{2}{|c|}{ Group I $(n=116)$} & \multicolumn{2}{|c|}{ Group II (n=93) } & \multirow[b]{2}{*}{$p$} \\
\hline & Mean \pm SD & Med (Min-Max) & Mean \pm SD & Med (Min-Max) & \\
\hline VAS & $6.1 \pm 2.5$ & $6(1-10)$ & $4.3 \pm 1.7$ & $4(1-10)$ & 0.000 \\
\hline Age & $61 \pm 13.1$ & $65(27-85)$ & $59 \pm 13.2$ & $60(28-83)$ & 0.060 \\
\hline Duration (sec) & $341 \pm 42.7$ & $350(250-400)$ & $342 \pm 51.1$ & $345(250-550)$ & 0.586 \\
\hline \multicolumn{6}{|l|}{ Cystoscopy reason } \\
\hline Bladder tumor control, n (\%) & $60(51.7 \%)$ & & $48(51.6 \%)$ & & 0.987 \\
\hline LUTS diagnostics, n (\%) & $56(48.3 \%)$ & & 45 (48.4\%) & & \\
\hline
\end{tabular}

minutes prior to the same gel instillation. All procedures were performed by a $15.5 \mathrm{f}$ flexible cystoscope by the same urologist. After the procedure, the patients were informed of the visual analog scale (VAS) consisting of 10 grades used to evaluate the pain they felt during the procedure, the results were recorded, and the groups were compared.

\section{Statistical Analysis}

The mean \pm standard deviation, median (minimum-maximum), frequency, and ratio values were used in descriptive statistics of the data. The distribution of the variables was measured with the Kolmogorov-Smirnov test. The Mann-Whitney $U$ test was used for the quantitative data analysis. The chi-squared test was used to analyze qualitative data. Data were analyzed using the Statistical Package for the Social Sciences version 22.0 program (IBM Corp., Armonk, $N Y$, USA). A $p<0.05$ was accepted as statistically significant.

\section{RESULTS}

The control cystoscopy for bladder tumor was performed in 116 (55.5\%) of the 209 patients included in the study, and the other 101 patients (44.5\%) underwent diagnostic cystoscopy for lower urinary symptoms. Group I included 116 patients, and Group II included 93 patients. The mean age of the patients in Group I was $61 \pm 13.1$ years (27-85; median, 65), while in Group II, it was $59 \pm 13.2$ years (28-83; median, 60). In Group I, the duration of cystoscopy was $341 \pm 42.7$ seconds (250-400; median, 350), while in Group II, it was 342 \pm 51.1 seconds (250-550; median, 345). There was no statistically significant difference between the two groups in terms of age and duration of the procedure $(p=0.60, p=0.586)$. The VAS value in Group I was $6.1 \pm 2.5(1-10$, median=6), while in Group II, it was 4.3 $\pm 1.7(1-10$, median=4). VAS values were significantly lower in the diclofenac group $(p=0.000)$ (Figure 1). The comparative data of the groups are summarized in Table 1.

\section{DISCUSSION}

Local cystoscopy is a widely used procedure in urology practice (5). Rigid cystoscopy may require sedation since it is a painful procedure, especially in male patients. In contrast, flexible cystoscopy is an easy, safe, effective, and less painful procedure, compared to rigid cystoscopy (6). In addition, it is possible to use less caliber instruments with flexible cystoscopy, making the examination possible with a more global view due to an increased patient tolerance as well as patient comfort (7). 
Urethral gel instillation in cystoscopy is used to ease the operation and pain relief. The lidocaine gel $2 \%$ has been used since 1949 (8). Afterwards, the dosing, application time, temperature, and many other parameters have been investigated by various studies. In studies, generally, $20 \mathrm{ml}$ of lidocaine gel has been shown to be more suitable than $10 \mathrm{ml}$ in terms of pain, and an average of $16 \mathrm{ml}$ was shown to be the most appropriate amount (9, 10). Again, several studies have shown that the retention of the gel in the urethra for 10-15 minutes is minimally more beneficial (4). However, since the mucosal absorption of transurethral topical analgesics is slow, it reaches the maximum level after 15-60 min. (11). Flexible cystoscopy has been shown to be more comfortable when the lidocaine gel is transurethrally administered for more than 15 minutes (12). In our study, we used $20 \mathrm{~mL}$ totally with a 15-minute waiting period.

While the procedure of the $\mathrm{J}$ stent removal in the pelvis with the help of a local ureteroscope, which is migrated toward the cranium, results in no difference in pain in both females and males, flexible cystoscopy is a more painful procedure due to the possible long urethral route in males $(13,14)$. We wanted to show the efficacy of diclofenac by taking only male patients and also by including a long urethral track into our study.

Komiya et al. (15) showed that the use of oral zaltoprofen effectively reduced the severity score of the local rigid cystoscopy. Similarly, oral diclofenac has been shown to have a pain-reducing effect during and for 24 hours after the $\mathrm{J}$ stent withdrawal procedure by local cystoscopy (16). Nadeem et al. (17) showed that the use of rectal suppository diclofenac effectively reduces the pain in flexible cystoscopy procedure. After surgical trauma, the cyclooxygenase-2 (COX-2) enzyme, which induces prostaglandin release that senses peripheral pain receptors, is induced. Subsequently, central sensitization and pain occur mainly through the N-methyl-D-aspartate (NMDA) and neurokinin receptors (18). NSAIDs inhibit the development of both peripheral and central sensitization and hyperalgesia by inhibiting the early production of prostanoids prior to surgical trauma more effectively. They also block nociceptive impulses, increase the threshold of nociceptive neurons by opioids, block the winding using NMDA receptor antagonists and suppress local inflammation. It is possible to produce a painless condition after surgery with NSAIDs $(18,19)$. Diclofenac and zaltoprofen have similar pharmacokinetic profiles. They are orally absorbed and bind to proteins. They are highly protein bound and are metabolized by UGT2B7 and CYP2C9. Most of the drug is biotransformed to the glyc-conjugate and sulfate metabolites, of which only a small fraction is eliminated in urine in an unchanged form. Diclofenac and zaltoprofen were found to have no local effect on the urinary tract $(20,21)$. We used only intramuscular diclofenac in the study. Diclofenac is a nonspecific COX inhibitor. Parenterally administered diclofenac reaches a maximum plasma level in a short time and its effect begins much faster than oral administration (22). Since patients are given diclofenac in advance, an analgesic effect starts shortly after, and flexible cystoscopy can be made more comfortably and painless in addition to lidocaine gel. In our study, we demonstrated that the use of intramuscular diclofenac prior to a flexible cystoscopy procedure was effective as a pain reducer.

\section{CONCLUSION}

Intramuscular diclofenac is a simple and effective method for reducing pain in flexible cystoscopy. We recommend routine use before flexible cystoscopy because of increased patient compliance and better pain tolerability.

Ethics Committee Approval: Authors declared that the research was conducted according to the principles of the World Medical Association Declaration of Helsinki "Ethical Principles for Medical Research Involving Human Subjects", (amended in October 2013).

Informed Consent: Written informed consent was obtained from patients who participated in this study.

Peer-review: Externally peer-reviewed.

Author Contributions: Concept - A.Ö.; Design - A.Ö.; Supervision - A.Ö., Ö.O.; Resources - A.K., A.I.H. ; Materials - A.K., M.B.C.B.; Data Collection and/or Processing - K.Ö.G., Ö.O.; Analysis and/or Interpretation - K.Ö.G.; Literature Search - N.C.Ç.; Writing Manuscript - A.Ö., N.C.Ç.; Critical Review - M.B.C.B., A.I.H

Conflict of Interest: The authors have no conflict of interest to declare.

Financial Disclosure: The authors declared that this study has received no financial support.

\section{REFERENCES}

1. Bhomi KK, Rizal S, Pradhan M, Rijal A, Bhattachan CL. Pain during rigid cystoscopy: a prospective randomized controlled study comparing the benefit of cooled and room temperature lignocaine gel. Nepal Med Coll J 2011; 13: 55-7.

2. Burke DM, Shackley DC, O'Reilly PH. The community-based morbidity of flexible cystoscopy. BJU Int 2002; 89: 347-9. [CrossRef]

3. Pliskin MJ, Kreder KJ, Desmond PM, Dresner ML. Cocaine and lidocaine as topical urethral anesthetics. J Urol 1989; 141: 1117-9. [CrossRef]

4. Birch BR, Ratan P, Morley R, Cumming J, Smart CJ, Jenkins JD. Flexible cystoscopy in men: is topical anaesthesia with lignocaine gel worthwhile? Br J Urol 1994; 73: 155-9. [CrossRef]

5. Gee JR, Waterman BJ, Jarrard DF, Hedican SP, Bruskewitz RC, Nakada SY. Flexible and rigid cystoscopy in women. JSLS 2009; 13: 135-8.

6. Fowler CG. Removal of ureteric stents with the flexible cystoscope. Br J Urol 1987; 60: 280. [CrossRef]

7. Denholm SW, Conn IG, Newsam JE, Chisholm GD. Morbidity following cystoscopy: comparison of flexible and rigid techniques. $\mathrm{Br} \mathrm{J}$ Urol 1990; 66: 152-4. [CrossRef]

8. Haines JS, Grabstald H. Xylocaine; a new topical anesthetic in urology. J Urol 1949; 62: 901-2. [CrossRef]

9. Holmes M, Stewart J, Rice M. Flexible cystoscopy: is the volume and content of the urethral gel critical? J Endourol 2001; 15: 855-8. [CrossRef]

10. Brekkan E, Ehrnebo M, Malmström PU, Norlén BJ, Wirbrant A. A controlled study of low and high volume anesthetic jelly as a lubricant and pain reliever during cystoscopy. J Urol 1991; 146: 24-7. [CrossRef]

11. Ouellette RD, Blute R Sr, Jaffee S, Bahde C. Plasma concentrations of lidocaine resulting from instillation of lidocaine jelly into genitourinary tract prior to cystoscopy. Urology 1985; 25: 490-1. [CrossRef]

12. Choong S, Whitfield HN, Meganathan V, Nathan MS, Razack A, Gleeson M.A. Prospective, randomized, double-blind study comparing lignocaine gel and plain lubricating gel in relieving pain during flexible cystoscopy. Br J Urol 1997; 80: 69-1. [CrossRef]

13. Livadas KE, Varkarakis IM, Skolarikos A, Karagiotis E, Alivizatos G, Sofras $F$, et al. Ureteroscopic removal of mildly migrated stents using local anesthesia only. J Urol 2007; 178: 1998-2001. [CrossRef] 
14. Goldfischer ER, Cromie WJ, Karrison TG, Naszkiewicz L, Gerber GS. Randomized, prospective, double-blind study of the effects on pain perception of lidocaine jelly versus plain lubricant during outpatient rigid cystoscopy. J Urol 1997; 157: 90-4. [CrossRef]

15. Komiya A, Endo T, Kobayashi M, Kim W, Araki K, Naya Y, et al. Oral analgesia by non-steroidal anti-inflammatory drug zaltoprofen to manage cystoscopy-related pain: A prospective study. Int J Urol 2009; 16: 874-80. [CrossRef]

16. Karthikeyan VS, Keshavamurthy R, Mallya A, Chikka Moga Siddaiah M, Kumar S, Chandrashekar CR. Efficacy of preprocedural diclofenac in men undergoing double $\mathrm{J}$ stent removal under local anesthesia: $\mathrm{A}$ double-blind, randomized control trial. Indian J Urol 2017; 33: 53-7.

17. Nadeem M, Ather MH. Effect of diclofenac suppository on pain control during flexible cystoscopy-A randomized controlled trial. F1000Res 2016; 5: 2834. [CrossRef]

18. Aida S, Baba H, Yamakura T, Taga K, Fukuda S, Shimoji K. The effectiveness of preemptive analgesia varies according to the type of surgery: A randomized, double-blind study. Anesth Analg 1999; 89: 711-6. [CrossRef]

19. Ong CK, Lirk P, Seymour RA, Jenkins BJ. The efficacy of preemptive analgesia for acute postoperative pain management: A meta-analysis. Anesth Analg 2005; 100: 757-73. [CrossRef]

20. Davies NM, Anderson KE. Clinical pharmacokinetics of diclofenac. Therapeutic insights and pitfalls. Clin Pharmacokinet 1997; 33: 184 213. [CrossRef]

21. Furuta S, Akagawa N, Kamada E, Hiyama A, Kawabata Y, Kowata N, et al. Involvement of CYP2C9 and UGT2B7 in the metabolism of zaltoprofen, a nonsteroidal anti-inflammatory drug, and its lack of clinically significant CYP inhibition potential. Br J Clin Pharmacol 2002; 54: 295-303. [CrossRef]

22. Idkaidek NM, Amidon GL, Smith DE, Nijab NM, Hassan MM. Determination of the population pharmacokinetic parameters of sustainedrelease and enteric-coated oral formulations, and the suppository formulation of diclofenac sodium by simultaneous data fitting using NONMEM. Biopharm Drug Dispos 1998; 19: 169-74. [CrossRef] 